\title{
Rancang Bangun Aplikasi Pengaduan Pelanggan Berbasis Web Menggunakan Framework Codeigniter Di Indotechno Purwokerto
}

\author{
Casro $^{\text {1), Yuli Purwati }}{ }^{2)}$, Gustin Setyaningsih ${ }^{3)}$, Adam Prayogo Kuncoro ${ }^{4)}$ \\ 1224) Informatika, Ilmu Komputer, Universitas Amikom Purwokerto \\ ${ }^{3)}$ Sistem Informasi, Ilmu Komputer, Universitas Amikom Purwokerto \\ J1. Letjend Pol. Soemarto, Watumas, Purwanegara, Kec. Purwokerto Utara, Kabupaten \\ Banyumas, Jawa Tengah 53127

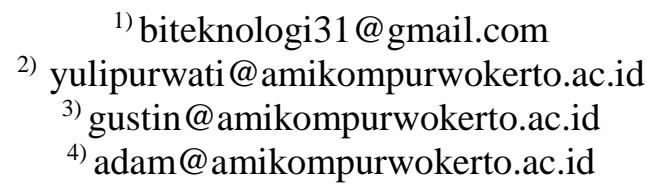

\begin{abstract}
Abstrak
Teknologi yang berkembang sangat cepat berpengaruh besar terhadap kehidupan manusia untuk kemudian dimanfaatkan dalam segala bidang, salah satunya bidang bisnis penyedia barang dan jasa. Indotechno Purwokerto merupakan perusahaan yang berfokus pada jasa penyedia kebutuhan hardware, maintenance, networking, multimedia dan security system. Proses pendataan aduan pelanggan di Indotechno Purwokerto masih menggunakan media kertas dan diolah menggunakan software Microsoft excel yang disimpan di komputer karyawan customer service, selain itu komputer karyawan yang bertugas melayani pengaduan sesuai dengan job descriptionription masing-masing belum saling terhubung satu sama lain. Selain itu pelanggan perusahaan Indotechno harus menghubungi secara langsung melalui call center atau dengan cara mendatangi kantor perusahaan Indotechno untuk menyampaikan keluhannya. Cara ini memiliki keterbatasan dikarenakan pengaduan hanya akan dilayani pada jam dan hari operasional perusahaan saja. Penelitian ini bertujuan untuk merancang dan membangun sebuah aplikasi pengaduan pelanggan berbasis web menggunakan framework codeigniter di perusahaan Indotechno Purwokerto. Pengumpulan data penelitian dilakukan dengan cara observasi, wawancara dan studi literatur. Metode pengembangan sistem menggunakan waterfall. Hasil penelitian ini adalah sebuah aplikasi pengaduan pelanggan berbasis website yang diharapkan dapat memberikan solusi agar pelayanan dan pengolahan data keluhan pelanggan dapat lebih cepat ditangani. Hasil pengujian blackbox menunjukkan bahwa semua fitur dalam aplikasi dapat berjalan sesuai harapan.
\end{abstract}

Kata kunci: aplikasi pengaduan, keluhan pelanggan, codeigniter, website.

\begin{abstract}
Technological developments that bring enormous advances to human life are used in all fields, one of the business areas of goods and service providers, especially companies to help complete the work of managing corporate data Indotechno Purwokerto is one of the companies engaged in providing goods and services services engaged in providing hardware, maintenance, network, multimedia and security system needs. The process of collecting customer complaints in Indotechno Purwokerto still uses paper media and is processed using Microsoft Excel software stored on one customer service operator computer and has not been integrated with the computers of other employees provided complaints according to their respective jobs. In addition, Indotechno company customers must contact directly through the call center or by visiting the Indotechno corporate office to submit their responses. This method has limitations considering
\end{abstract}


observation and literature study. The system development method uses a waterfall. The result of this research is a website-based customer complaint application which is expected to provide solutions so that customer complaint data processing and services can be handled more quickly. The blackbox test results show that all the features in the application can run as expected.Complaints will only discuss the hours and days of the company's operations. To overcome this problem, the writer will discuss and make a complaint application about the web using a codeigniter framework in the Indotechno Purwokerto Company. Methods of data collection using interviews,

Keywords: Complaint application, customer complaint, codeigniter, website.

\section{PENDAHULUAN}

Teknologi yang berkembang sangat cepat berpengaruh besar terhadap kehidupan manusia, teknologi komputer dan internet merupakan salah satu teknologi yang digunakan untuk mengatasi berbagai masalah baik di bidang industri, kesehatan, pendidikan dan hiburan. Pemanfaatan teknologi di perusahaan jasa biasanya digunakan untuk membantu menyelesaikan pekerjaan pengelolaan data contohnya seperti data pelanggan, data keluhan pelanggan dan data hasil tindak lanjut atas keluhan yang disampaikan oleh pelanggan.

Indotechno Purwokerto merupakan perusahaan penyedia barang dan jasa yang berfokus pada jasa penyedia kebutuhan hardware, maintenance, networking, multimedia dan security system. Saat ini proses pendataan aduan pelanggan di perusahaan Indotechno masih menggunakan media kertas dan diolah menggunakan software Microsoft excel yang disimpan di komputer karyawan customer service, selain itu komputer karyawan yang bertugas melayani pengaduan sesuai dengan job description masing-masing belum saling terhubung satu sama lain. Selain itu pelanggan perusahaan Indotechno harus menghubungi secara langsung melalui call center atau dengan cara mendatangi kantor perusahaan Indotechno untuk menyampaikan keluhannya. Cara ini memiliki keterbatasan dikarenakan pengaduan hanya akan dilayani pada jam dan hari operasional perusahaan saja. Dengan penggunaan sistem yang manual tersebut, sangat berpengaruh terhadap alur kerja dari karyawan karena data pelanggan harus diolah minimal dua kali oleh karyawan. Data-data pelanggan yang sudah dicatat harus disortir oleh karyawan bagian customer service kemudian diteruskan kepada karyawan lapangan untuk ditindak lanjuti sesuai dengan job description yang bersangkutan.

Untuk mengatasi permasalahan tersebut maka diperlukan suatu aplikasi yang dirancang khusus untuk menangani proses pengaduan pelanggan dan proses pengolahan data aduan pelanggan. Dengan aplikasi ini karyawan yang bertugas untuk menerima dan mengolah data aduan pelanggan tidak perlu lagi mencatat pada media kertas dan mengolahnya menggunakan software microsoft excel, karyawan hanya membutuhkan satu aplikasi untuk menangani semua pekerjaan terkait dengan pengelolaan data aduan pelanggan, pembagian tugas pekerja lapangan, serta proses pembuatan laporan. Dengan aplikasi tersebut diharapkan proses pengelolaan data aduan pelanggan dapat berjalan lebih cepat, tepat dan terstruktur sesuai job description masingmasing. Selain itu dengan aplikasi ini pelanggan tidak perlu mendatangi kantor perusahaan Indotechno saat akan menyampaikan aduan terkait produk yang dipakainya, pelanggan hanya tinggal mengakses platform yang disediakan perusahaan dan menuliskan aduannya pada form yang tersedia.

Berdasarkan uraian tersebut tujuan penelitian ini adalah untuk merancang dan membangun sebuah aplikasi pengaduan pelanggan berbasis web menggunakan framework codeigniter di perusahaan Indotechno Purwokerto. Aplikasi pengaduan pelanggan diharapkan memberikan solusi agar pelayanan dan pengolahan data pelanggan dapat lebih cepat, tepat, efektif, dan terstruktur. 


\section{TINJAUAN PUSTAKA}

\subsection{Rancang Bangun}

Rancang bangun adalah aktifitas mentranformasikan hasil analisis sistem ke dalam bentuk perangkat lunak kemudian membangun sistem tersebut atau memperbaiki serta mengembangkan sistem yang sudah ada sebelumnya [1].

\subsection{Aplikasi}

Secara umum aplikasi adalah perangkat lunak yang memiliki kemampuan khusus dan diterapkan pada sebuah perangkat komputer/telepon pintar agar dapat digunakan oleh user [2].

\subsection{Keluhan Pelanggan}

Perilaku pengaduan konsumen atau pelanggan (consumer complaint behavior) merupakan semua tindakan pelanggan yang dilakukan sebagai akibat ketidakpuasan pelanggan terhadap pembelian suatu produk suatu produsen atau pelayanan yang diterima dari perusahaan. Keluhan diajukan karena adanya perasaan kecewa atau tidak puas terhadap kualitas sebuah produk atau pelayanan yang diberikan oleh suatu perusahaan. Jenis perilaku pengaduan terdiri dari rencana untuk melakukan pengaduan, ujaran negatif tentang produk/jasa, dan rencana untuk memilih produk/jasa lain [3].

\subsection{Pelayanan}

Pelayanan adalah aktifitas yang tidak dapat digambarkan secara tersendiri karena pada bersifat intangible (tidak teraba), pelayanan merupakan bentuk pemenuhan kebutuhan dan tidak harus terikat pada penjualan produk atau pelayanan lain. Pelayanan berasal dari kata dasar "layan" yang artinya dalam Kamus Besar Bahasa Indonesia adalah menyiapkan, setelah mendapatkan imbuhan dan akhiran maka membentuk kata kerja "melayani" berarti membantu menyediakan (mengurus) apa yang diperlukan seseorang [4].

\subsection{Website}

Website atau disingkat web, dapat diartikan beberapa halaman di internet yang berisi informasi dalam bentuk data digital baik berupa text, gambar, video, suara dan animasi lainnya [5] .

\section{METODE PENELITIAN}

\subsection{Metode Pengumpulan Data}

Dalam upaya mencapai tujuan penelitian yang nantinya menjadi sebuah aplikasi manajemen pengaduan pelanggan berbasis website menggunakan framework codeigniter di perusahaan Indotechno, maka peneliti melakukan metode pengumpulan data dan informasi yang menunjang penelitian ini yaitu teknik wawancara, observasi dan studi pustaka.

a. Metode Wawancara

Pada tahapan ini, peneliti melakukan wawancara dengan direktur dari perusahaan Indotechno Purwokerto terkait pembuatan aplikasi manajemen pengaduan pelanggan, yaitu Bapak Heri Sartono. Wawancara yang dilakukan dengan pemilik dari perusahaan Indotechno Purwokerto guna mencari informasi mengenai kebutuhan aplikasi sehingga peneliti memiliki gambaran yang nantinya menjadi dasar dalam pembuatan aplikasi manajemen pengaduan pelanggan berbasis website dengan framework codeigniter ini.

b. Metode Observasi

Observasi dilakukan dengan cara mengamati serta mencatat hal-hal yang berkaitan dengan penelitian. Pada tahap observasi peneliti mengamati dan mencatat proses penyampaian aduan pelanggan, proses pengolahan data aduan pelanggan dan proses tindak lanjut atas aduan yang diajukan oleh pelanggan di perusahaan Indotechno. 
c. Metode Studi Pustaka

Dalam penelitian ini studi pustaka yang dilakukan peneliti dengan membaca jurnal, buku maupun web yang berkaitan dengan penelitian dari berbagai sumber untuk melengkapi bahan penelitian, dan panduan pembuatan penelitian akhir ini.

\subsection{Metode Pengembangan Sistem}

Metode pengembangan sistem yang dilakukan dalam penelitian ini adalah metode waterfall. yang mana metode tersebut menyediakan pendekatan alur hidup perangkat lunak secara sekuensial atau terurut [6]. Berikut adalah gambar model waterfall:

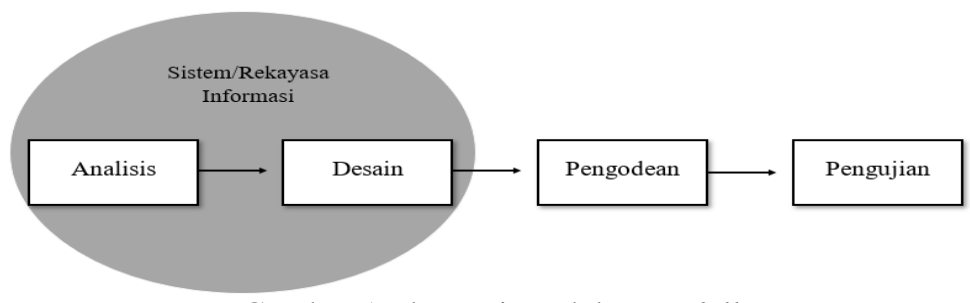

Gambar 1. Ilustrasi model waterfall

\subsubsection{Analisis}

Proses pengumpulan kebutuhan dilakukan secara intensif untuk menspesifikasikan kebutuhan perangkat lunak agar dapat dipahami seperti apa yang dibutuhkan oleh user. Spesifikasi kebutuhan perangkat lunak pada tahap ini perlu didokumentasikan, diawali dengan analisis proses bisnis usulan yang disesuaikan dengan kebutuhan user. Selanjutnya menganalisis kebutuhan sistem yaitu menganalisis hardware dan software apa yang sesuai dengan penelitian.

\subsubsection{Desain}

Desain merupakan tahapan pembuatan program perangkat lunak yang meliputi pembuatan struktur data, kerangka perangkat lunak, tampilan antarmuka dan pengkodean. Pada tahapan ini kebutuhan perangkat lunak yand dimulai dari tahap analisis kebutuhan akan ditranformasikan ke representasi desain supaya pada tahap selanjutnya dapat di terapkan dalam bentuk program serta mendokumentasikan desain yang telah dihasilkan.

\subsubsection{Pengkodean}

Desain yang telah dibuat harus diterjemahkan ke dalam program perangkat lunak. Tahapan ini akan menghasilkan program komputer yang merupakan representasi dari tahap desain.

\subsubsection{Pengujian}

Tahap pengujian berfungsi untuk mengurangi kesalahan/error serta menghasilkan output yang sesuai dengan harapan. Pengujian dapat dilakukan dari sisi logik dan fungsional serta menguji semua bagian/fitur pada aplikasi. Metode pengujian yang digunakan pada penelitian ini adalah metode blackbox testing yang berfunngsi untuk menguji fungsionalitas sistem yang dibangun.

\section{PEMBAHASAN}

\subsection{Analisis}

\subsubsection{Analisis Kebutuhan Pengguna}

Tahapan ini berguna agar proses pengembangan aplikasi tepat sasaran dan berfungsi dengan baik sebagai aplikasi pengaduan pelanggan berbasis web menggunakan framework codeigniter. Adapun hasil analisis kebutuhan pengguna adalah sebagai berikut:

a. Aplikasi dapat digunakan untuk mengolah data laporan aduan pelanggan.

b. Aplikasi dapat digunakan untuk mengolah data divisi karyawan dan data karyawan/teknisi. 
c. Aplikasi dapat digunakan oleh pelanggan untuk melaporkan gangguan terkait produk yang dipakainya.

d. Aplikasi dapat digunakan oleh admin untuk menerima laporan gangguan dari pelanggan dan diteruskan kepada teknisi sesuai divisi.

e. Aplikasi dapat digunakan oleh teknisi untuk menerima laporan gangguan sesuai dengan divisi karyawan.

f. Aplikasi dapat digunakan untuk mencari informasi laporan gangguan.

g. Aplikasi dapat digunakan untuk mendata jumlah laporan gangguan setiap periode.

h. Aplikasi dapat menampilkan data aduan pelanggan, data divisi, data karyawan, data pelanggan, data jumlah laporan gangguan yang diterima setiap periode, data laporan gangguan yang belum dikerjakan, sedang dalam proses pengerjaan dan laporan gangguan yang selesai dikerjakan oleh teknisi.

\subsubsection{Analisis Kebutuhan Hardware dan Software}

Analisis spesifikasi dilakukan untuk mengetahui perangkat yang tersedia di perusahaan Indotechno Purwokerto agar aplikasi pengaduan pelanggan berbasis web menggunakan framework codeigniter dapat dijalankan. Pada penelitian ini, kebutuhan spesifikasi hardware yang digunakan meliputi Processor AMD Ryzen 5 2400G with Radeon Vega Graphics (8 CPUs), $\sim 3.6 \mathrm{GHz}$, memory $8192 \mathrm{MB}$, SSD $120 \mathrm{~GB}$, VGA Card AMD Radeon(TM) RX Vega 11 Graphics, dan Printer Canon G2010. Sedangkan kebutuhan Software yang digunakan meliputi Sistem Operasi Windows, Xampp web server dan web browser.

\subsection{Desain}

\subsubsection{Use Case Diagram}

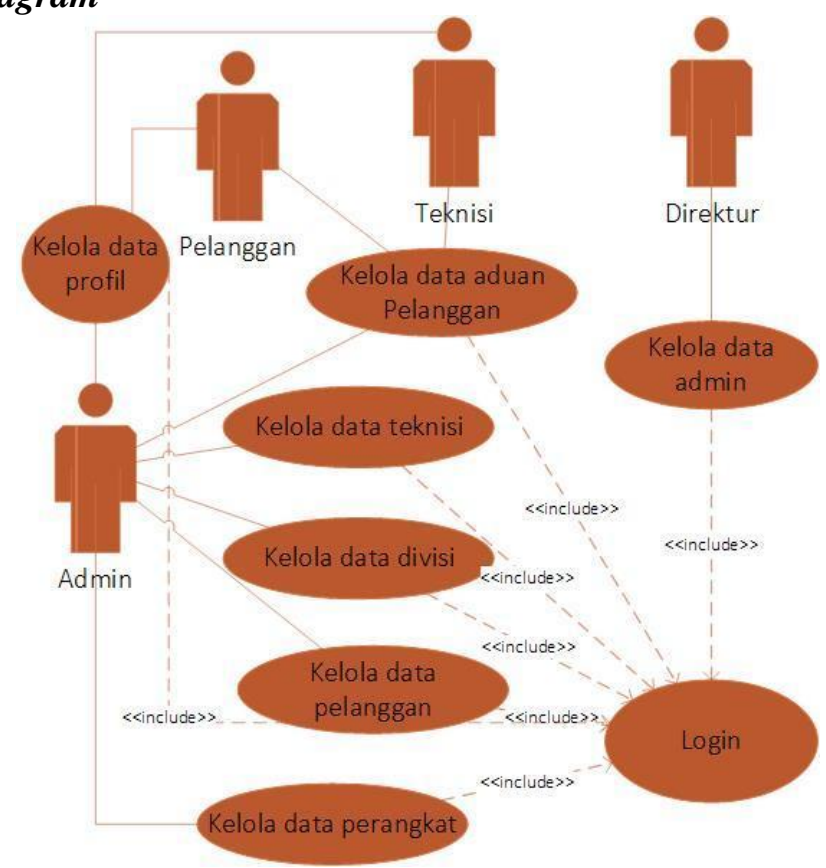

Gambar 2. Use case diagram aplikasi

Gambar 2 merupakan use case diagram yang menggambarkan pemodelan untuk memahami alur sistem yang dibangun. Dalam use case diagram ini memiliki 4 aktor yaitu aktor pelanggan, aktor admin, aktor teknisi dan aktor direktur. Aktor pelanggan merupakan orang yang membuat laporan gangguan terkait barang dan jasa dari perusahaan Indotechno Purwokerto. Aktor admin merupakan orang yang bertugas untuk menerima laporan gangguan dari pelanggan dan meneruskannya kepada teknisi lapangan sesuai dengan divisi pekerjaan. Aktor admin juga bertugas untuk mengelola data divisi, data teknisi, data pelanggan dan data laporan gangguan. 
Aktor teknisi merupakan orang yang akan turun ke lapangan untuk memperbaiki gangguan yang yang dilaporkan oleh pelanggan. Aktor teknisi akan menerima, dan merubah status laporan gangguan yang sedang dikerjakannya. Aktor direktur merupakan user dari pemilik perusahaan yang akan memantau semua data laporan yang diolah oleh aplikasi dan juga direktur berhak untuk mengelola data admin.

\subsection{Pengodean}

\subsubsection{Halaman Login}

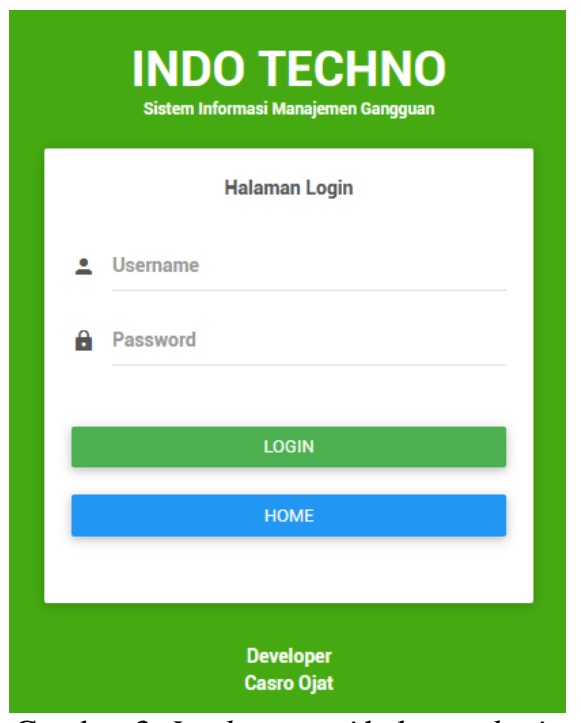

Gambar 3. Implementasi halaman login

Gambar 3 merupakan tampilan halaman login. Halaman ini digunakan untuk melakukan proses login dengan memasukkan username dan password.

\subsubsection{Halaman Pelanggan}

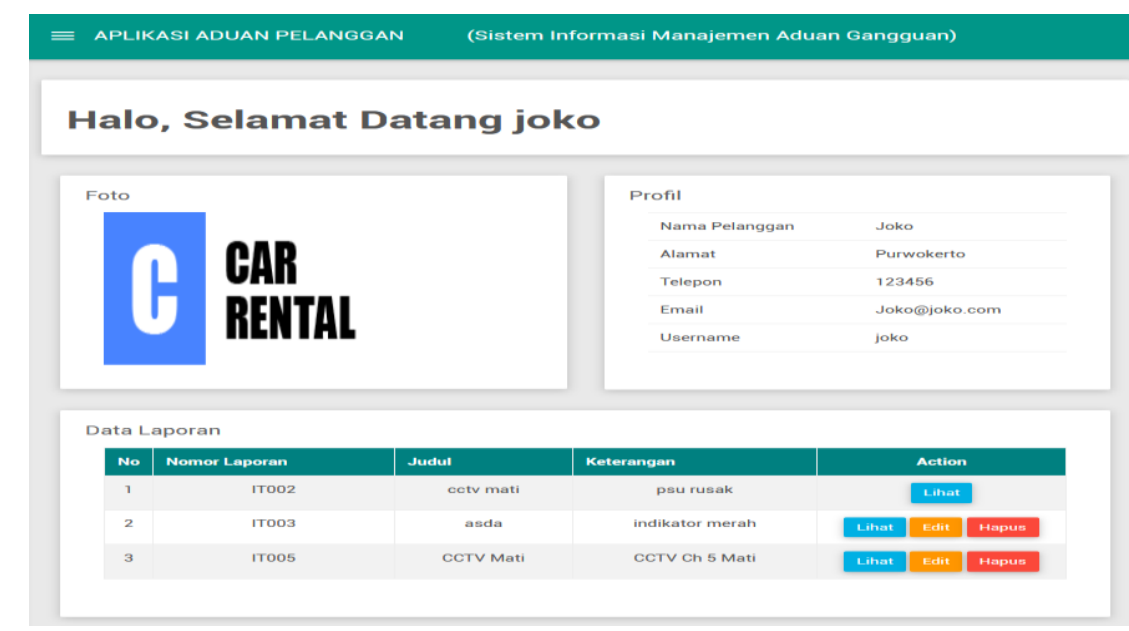

Gambar 4. Implementasi halaman pelanggan

Gambar 4 merupakan tampilan implementasi halaman pelanggan. Pada halaman ini pelanggan dapat melihat profil, mengedit profil melakukan aduan gangguan, mengedit aduan gangguan dan melihat aduan gangguan. 


\subsubsection{Halaman Admin}

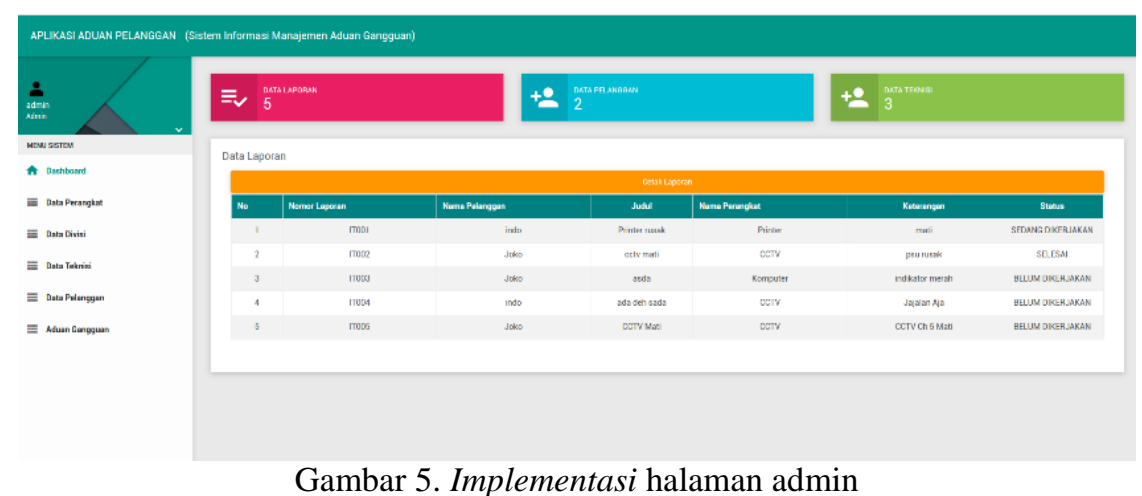

Gambar 5 merupakan tampilan implementasi halaman admin. Pada halaman ini admin dapat mencetak laporan aduan gangguan, memilih teknisi, melihat profil admin, mengelola data perangkat, mengelola data divisi, mengelola data teknisi dan mengelola data pelanggan.

\subsubsection{Halaman Teknisi}

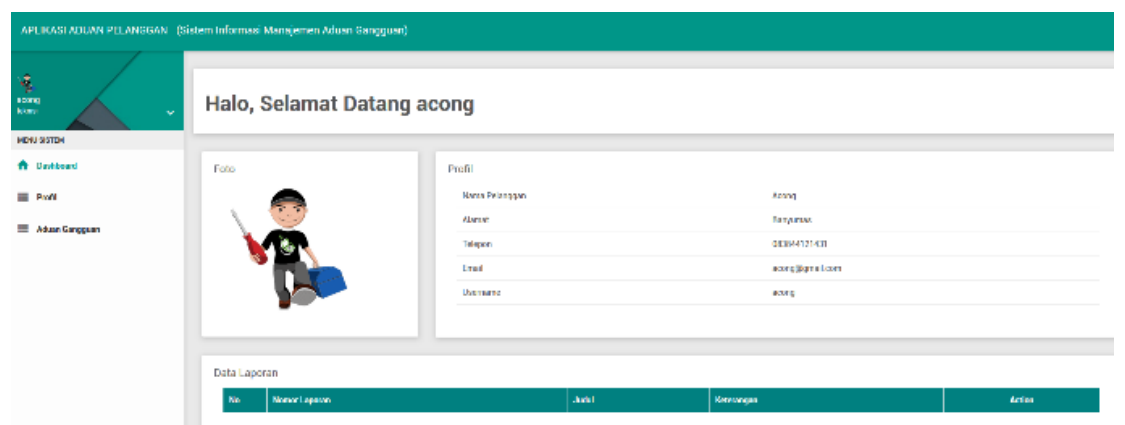

Gambar 6. Implementasi halaman teknisi

Gambar 6 merupakan tampilan implementasi halaman teknisi. Pada halaman ini teknisi dapat melihat profil teknisi, melihat aduan gangguan, update status aduan gangguan dan menambah kegiatan.

\subsubsection{Halaman Direktur}

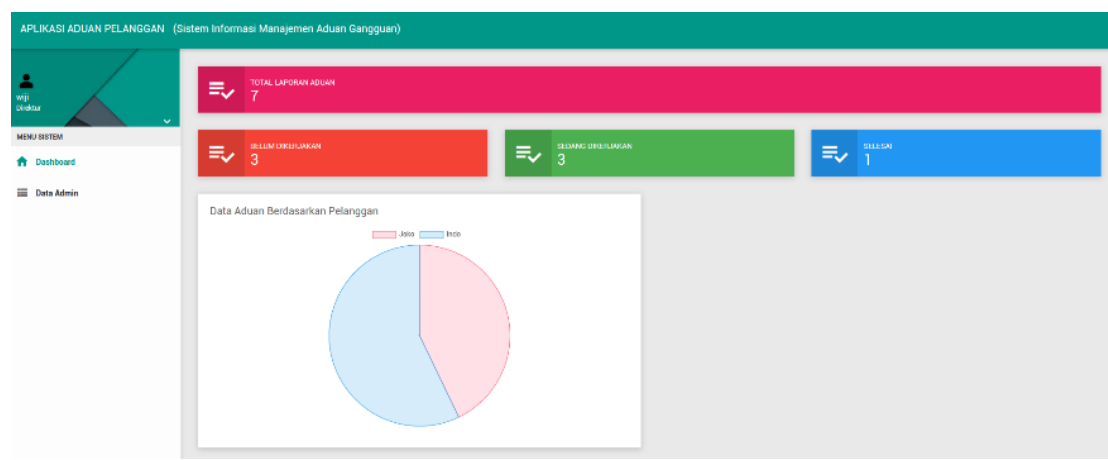

Gambar 7. Implementasi halaman direktur

Gambar 7 merupakan tampilan implementasi halaman direktur. Pada halaman ini direktur dapat mengelola, menambah dan mengedit data admin. Pada halaman utama dashboard 


\subsection{Pengujian}

Pengujian sistem menggunakan pengujian metode blackbox testing sistem pada aplikasi pengaduan pelanggan berbasis web menggunakan framework codeigniter. Hasil pengujian dapat dilihat pada tabel 1 berikut:

Tabel 1. Hasil pengujian blackbox

\begin{tabular}{|c|c|c|c|c|}
\hline No & Actor & Kelas Uji & Butir Uji & Hasil \\
\hline 1. & Semua aktor & $\begin{array}{l}\text { Menampilkan halaman } \\
\text { utama website }\end{array}$ & $\begin{array}{l}\text { Tampilan halaman utama } \\
\text { website }\end{array}$ & Valid \\
\hline 2. & Semua aktor & Login & Verifikasi & Valid \\
\hline 3. & Semua aktor & $\begin{array}{l}\text { Menampilkan halaman } \\
\text { utama dashboard aktor }\end{array}$ & Dashboard & Valid \\
\hline 4. & Semua aktor & Mengelola profil & Tampil dan ubah data & Valid \\
\hline 5. & Pelanggan & $\begin{array}{l}\text { Membuat dan mengelola } \\
\text { laporan gangguan }\end{array}$ & $\begin{array}{l}\text { Tampil, simpan, ubah dan } \\
\text { hapus data }\end{array}$ & Valid \\
\hline 6. & Admin & $\begin{array}{l}\text { Mengelola data aduan } \\
\text { pelanggan }\end{array}$ & $\begin{array}{l}\text { Tampil, simpan dan ubah } \\
\text { data }\end{array}$ & Valid \\
\hline 7. & Admin & Mengelola data divisi & $\begin{array}{l}\text { Tampil, simpan, ubah dan } \\
\text { hapus data }\end{array}$ & Valid \\
\hline 8. & Admin & Mengelola data teknisi & $\begin{array}{l}\text { Tampil, simpan, ubah dan } \\
\text { hapus data }\end{array}$ & Valid \\
\hline 9. & Admin & Mengelola data perangkat & $\begin{array}{l}\text { Tampil, simpan, ubah dan } \\
\text { hapus data }\end{array}$ & Valid \\
\hline 10. & Admin & Mengelola data pelanggan & $\begin{array}{l}\text { Tampil, simpan, ubah dan } \\
\text { hapus data }\end{array}$ & Valid \\
\hline 11. & Teknisi & $\begin{array}{l}\text { Mengelola data aduan } \\
\text { pelanggan }\end{array}$ & $\begin{array}{l}\text { Tampil, ubah data, dan } \\
\text { simpan }\end{array}$ & Valid \\
\hline 12. & Direktur & $\begin{array}{l}\text { Menampilkan statistik } \\
\text { laporan gangguan }\end{array}$ & Tampil data & Valid \\
\hline 13. & Direktur & Mengelola data admin & $\begin{array}{l}\text { Tampil, simpan, ubah dan } \\
\text { hapus data }\end{array}$ & Valid \\
\hline
\end{tabular}

Ket: Jumlah kelas uji (a) $=13$

Jumlah kelas uji yang hasilnya valid $(b)=13$

Perhitungan pengujian $=\frac{b}{a} \times 100 \%=100 \%$

Hasil pengujian diatas menunjukkan $100 \%$ fungsionalitas sistem berjalan dengan baik dan sesuai dengan harapan.

\section{KESIMPULAN}

Setelah dilakukannya penelitian terhadap permasalahan yang terjadi di Perusahaan Indotechno, maka dapat diambil kesimpulan sebagai berikut:

a. Penelitian ini telah berhasil membangun aplikasi aduan pelanggan dengan fitur mengelola data aduan pelanggan, data perangkat, data divisi, data teknisi, data pelanggan, dan data admin.

b. Aplikasi aduan pelanggan menghasilkan output berupa laporan gangguan dengan periode yang ditentukan sesuai kebutuhan.

c. Hasil pengujian blackbox menunjukkan $100 \%$ fungsionalitas sistem berjalan dengan baik dan sesuai dengan harapan 


\section{DAFTAR PUSTAKA}

[1] E. Lestariningsih, E. Ardhianto, and W. T. Handoko, "Rancang Bangun E-Office Administrasi Surat Di Bagian Humas Universitas Stikubank Semarang," J. Din. Inform., vol. 7, no. 2, pp. 102-108, 2015.

[2] H. F. Siregar, Y. H. Siregar, and M. Melani, "Perancangan Aplikasi Komik Hadist Berbasis Multimedia," J. Teknol. Inf., vol. 2, no. 2, p. 113, 2019.

[3] C. Prianto and S. Bunyamin, Panduan Pembuatan Aplikasi Clustering Gangguan Jaringan Menggunakan Metode K-Means Clustering, 1st ed. Bandung: Kreatif Industri Nusantara, 2020.

[4] S. Indriyani and S. Mardiana, "Pengaruh Penanganan Keluhan (Complaint Handling) Terhadap Kepercayaan Dan Komitmen Mahasiswa Pada Perguruan Tinggi Swasta Di Bandar Lampung,” J. Bisnis Darmajaya, vol. 2, no. 1, 2016.

[5] R. Abdulloh, Easy \& Simple Web Programming. Jakarta: Elex Media Komputindo, 2016.

[6] A. S. Rosa and M. Shalahudin, Rekayasa Perangkat Lunak Terstruktur dan Berorientasi Objek Edisi Revisi. Bandung: Informatika, 2018.

\section{Biodata Penulis}

Casro, dilahirkan di Cilacap, 31 Agustus 1997. Menempuh pendidikan dimulai dari SD Negeri Pengadegan (lulus tahun 2009), melanjutkan ke SMP Negeri 4 Majenang (lulus tahun 2012) dan lanjut SMK Komputama Majenang jurusan Teknik Komputer dan Jaringan (lulus tahun 2015). Saat ini menempuh pendidikan di Universitas Amikom Purwokerto Program Studi Informatika dan sedang menyelesaikan Tugas Akhir untuk memperoleh gelar S.Kom.

Yuli Purwati, lahir di Banyumas pada tanggal 17 Juli 1987. Meraih gelar Sarjana Komputer (S.Kom) di Program Studi Teknik Informatika dari STMIK AMIKOM Purwokerto pada tahun 2010 dan gelar Magister Komputer (M.Kom) di Magister Teknik Informatika STMIK AMIKOM Yogyakarta pada tahun 2013. Saat ini berprofesi sebagai Dosen di Program Studi Informatika Universitas Amikom Purwokerto.

Gustin Setyaningsih, lahir di Padang Pariaman pada tanggal 23 Agustus 1991. Meraih gelar Sarjana Komputer (S.Kom) di Program Studi Sistem Informasi dari STMIK AMIKOM Purwokerto pada tahun 2014 dan gelar Magister Manajemen Sistem Informasi (M.MSI) di Magister Manajemen Sistem Informasi Bina Nusantara Jakarta pada tahun 2016. Saat ini berprofesi sebagai Dosen di Program Studi Sistem Informasi Universitas Amikom Purwokerto.

Adam Prayogo Kuncoro, lahir di Semarang pada tanggal 15 Agustus 1990. Meraih gelar Sarjana Komputer (S.Kom.) di Program Studi Sistem Informasi dari STMIK AMIKOM Purwokerto pada tahun 2013 dan gelar Magister Komputer (M.Kom.) di Magister Ilmu Komputer, Universitas Islam Indonesia, Yogyakarta pada tahun 2016. Saat ini berprofesi sebagai Dosen di Program Studi Informatika, Universitas Amikom Purwokerto. 